\title{
Understanding lactose behaviour during storage by monitoring surface energy change using inverse gas chromatography
}

\author{
Shyamal Das ${ }^{1}$, Ian Larson ${ }^{1}$, Paul Young ${ }^{2}$, Peter Stewart ${ }^{1 *}$ \\ ${ }^{1}$ Drug Delivery, Disposition and Dynamics, Monash Institute of Pharmaceutical Sciences, \\ Monash University (Parkville campus), 381 Royal Parade, Victoria 3052, Australia \\ ${ }^{2}$ Advanced Drug Delivery Group, Faculty of Pharmacy, University of Sydney, NSW 2006, Australia
}

\begin{abstract}
Received 3rd July 2009 - Revised 9 November 2009 - Accepted 10 November 2009
Published online 19 January 2010
\end{abstract}

\begin{abstract}
The purposes of this research were to use inverse gas chromatography (IGC) to examine surface energy changes to coarse lactose (CL) and micronized lactose (ML) during storage at high humidity and to relate these changes to powder properties. Surface energies, work of cohesion and surface heterogeneity were determined by IGC. Surface morphology, particle size distributions and amorphous content were determined by scanning electron microscopy, laser diffraction and time-of-flight particle sizing and dynamic vapour sorption, respectively. Surface energies (dispersive, polar and total) were higher for ML than for CL. Surface heterogeneity profiles indicated a greater number of energy sites on ML. No detectable amorphous content was present in lactoses. After storage at $75 \%$ relative humidity, the particle size increased and the span of distribution decreased for ML, indicating the formation of small agglomerates. The ability of agglomerated ML to disperse decreased after storage, indicating the formation of strong agglomerates during storage. The dispersive surface energies of CL and ML significantly decreased after storage $(P<0.05)$, while the polar surface energies significantly increased $(P<0.05)$. The total surface energy and work of cohesion of ML increased. IGC was useful to distinguish between lactose powders; the total surface energy and work of cohesion of ML were higher than those of CL. While the increase in total surface energy and work of cohesion of ML after storage was in good agreement with the formation of stronger agglomerates, these changes may have been associated more with moisture adsorption than with inherent surface energy changes to lactose.
\end{abstract}

lactose / inverse gas chromatography / surface energy / relative humidity / storage

摘要 一 反相气相色谱法检测乳糖贮藏期间表面能的变化及乳糖特性的研究。本文研究了在 高湿环境下聍藏的粗鋉和微细化乳糖表面能的变化, 以及表面能变化对乳糖粉末特性的 影响。采用反相气相色谱法检测了表面能、内聚力和表面不均匀性; 通过扫描电镜、激光散 射、粒子飞行时间和蒸汽吸附动力学方法研究了乳糖的表面形态、颗粒分布以及不定形结 构的含量。微细化乳糖的表面能 (色散分量、极性分量和总表面能) 高于粗䊁乳糖。表面多 相性的研究结果显示了在微细化乳糖的表面有很多能量位点。在两种乳糖样品中没有检 测到无定形态乳糖的存在。在 $75 \%$ 的相对湿度下，微细化乳糖的粒度增加、粒度分布变 窄，并形成了小的聚集物。由于贮藏期间乳糖颗粒的聚集作用较强，使得聚集乳糖的分散 能力下降。㫟藏后粗粘乳糖和微细化乳糖的色散分量显著地降低 $(P<0.05)$, 而极性分量则 显著地增加 $(P<0.05)$ 。微细化乳糖的总表面能和内聚力增加。总之, 由于败藏过程中乳糖颗

*Corresponding author (通讯作者): Peter.Stewart@pharm.monash.edu.au 
粒间较强的聚集作用使得微细化乳糖的表面能和内聚力增加, 使得微细化乳糖的总表面能 和内聚力高于粗粘乳糖。因此, 水分吸收作用引起的变化高于乳糖固有表面能的变化。

\title{
乳糖 / 反相气相色谱 / 表面能 / 相对湿度 / 贮藏
}

\begin{abstract}
Résumé - Compréhension du comportement du lactose au cours du stockage en suivant le changement d'énergie de surface par chromatographie gazeuse en phase inverse. Le but de cette recherche était d'utiliser la chromatographie gazeuse en phase inverse (CGI) pour examiner les changements d'énergie de surface de lactose brut ou micronisé au cours du stockage à humidité élevée et de relier ces changements aux propriétés de la poudre. Les énergies de surface, l'aptitude à la cohésion et l'hétérogénéité de surface ont été déterminées par CGI. La morphologie de surface, les distributions de tailles de particules et la teneur en lactose amorphe ont été déterminées respectivement par microscopie électronique à balayage, diffraction laser et mesure des particules en temps de vol et sorption de vapeur en dynamique. Les énergies de surface (dispersive, polaire et totale) étaient plus élevées pour le lactose micronisé que pour le lactose brut. Les profils d'hétérogénéité de surface indiquaient un plus grand nombre de sites d'énergie sur le lactose micronisé. Aucun des lactoses ne présentait de teneur en lactose amorphe détectable. Après stockage à $75 \%$ d'humidité relative, la taille des particules augmentait et l'étendue de distribution diminuait pour le lactose micronisé indiquant la formation de petits agglomérats. L'aptitude du lactose micronisé aggloméré à se disperser diminuait après stockage indiquant la formation d'agglomérats forts au cours du stockage. Les énergies de surface dispersives du lactose brut et du lactose micronisé diminuaient significativement après stockage $(P<0,05)$, tandis que les énergies de surface polaires augmentaient significativement $(P<0,05)$. L'énergie de surface totale et l'aptitude à la cohésion du lactose micronisé augmentaient. La CGI était utile pour différencier les poudres de lactose ; l'énergie de surface totale et l'aptitude à la cohésion du lactose micronisé étaient plus élevées que celles du lactose brut. L'augmentation de l'énergie de surface totale et l'aptitude à la cohésion du lactose micronisé après stockage étaient bien corrélées à la formation d'agglomérats plus forts, mais ces changements seraient plus à relier à l'adsorption d'humidité qu'aux changements d'énergie de surface inhérents au lactose.
\end{abstract}

lactose / chromatographie gazeuse en phase inverse / énergie de surface / humidité relative / stockage

\section{INTRODUCTION}

Lactose is a commonly used pharmaceutical excipient in solid dosage forms, such as tablets, capsules and dry powder formulations, and is used to increase bulk and powder flow. The typical sizes of the coarse lactose particles that are used as carriers for drugs in dry powder formulations range from 50 to $150 \mu \mathrm{m}[4,14]$. Recently, fine lactoses with a particle size $<10 \mu \mathrm{m}$ have been used to improve the drug delivery efficiency of dry powder inhaler formulations $[15,16]$. These fine lactoses are usually produced by the micronization of commercial coarse lactoses. Coarse lactose and micronized lactose (ML) vary in their surface properties due to surface crystal dislocation and development of amorphous domains on the surface during processing or due to the orientation of chemical groups on the surface [18]. Thus, the surface energy that is related to the adhesive/ cohesive character of particles will be different. In general, the powder will be more cohesive if the surface energy is higher. Micronized lactose usually exists as agglomerates due to the balance of the cohesive/ detachment forces [17]. After storage at high relative humidity $(\mathrm{RH})$, the surface energy of powders can change [20]. There may be a differential change between coarse and fine lactose, which may have an effect on their functionality. In particular, for ML, the agglomerate characteristics such as the extent of interaction could be different after storage and this is likely to change the 
product performance. Understanding the relationship between surface energy and product performance is, therefore, important.

Surface energy $(\gamma)$ can be defined as the energy required to produce a unit area of surface. All materials have non-polar interaction sites, and most materials have polar interaction sites [13]. Thus, the surface energy $(\gamma)$ is the sum total of dispersive $\left(\gamma^{\mathrm{D}}\right)$ and polar components $\left(\gamma^{\mathrm{P}}\right)$

$$
\gamma=\gamma^{\mathrm{D}}+\gamma^{\mathrm{P}} \text {. }
$$

Among the available options for surface energy determination, inverse gas chromatography (IGC) is considered to be one of the best techniques for measurement of surface energy [18]. The material to be investigated is placed in the chromatographic column, and test solutes (probes) are transported over the surface by a carrier gas. The dispersive surface energy is calculated using a series of alkanes as probes according to the method described by Schultz et al. [23]. If only dispersive forces are present and the adsorbed probe is treated as a thin liquid film, the relationship between the net retention volume and free enthalpy or energy of adsorption $(\Delta G)$ is given by

$$
\Delta G=\mathrm{RT} \ln \mathrm{V}_{\mathrm{N}}+\mathrm{C},
$$

where $\mathrm{R}$ is the gas constant and $\mathrm{C}$ is another constant that depends on a chosen reference state. The free energy of adsorption, $\Delta G$, can also be related to the energy of adhesion $\left(W_{\mathrm{A}}\right)$ between a probe molecule and a substrate by the following equation:

$$
\Delta G=N_{\mathrm{A}} a W_{\mathrm{A}},
$$

where $N_{\mathrm{A}}$ is Avogadro's number and $a$ is the area of surface occupied by one probe molecule. Dispersive interactions are dominant when alkanes are used as probes, and there is no difference between $\Delta G$ and $\Delta G^{\mathrm{D}}$ (energy of adsorption for dispersive interactions). Thus, the work of adhesion
$\left(W_{\mathrm{A}}\right)$ can be calculated from the dispersive surface energies of the substrate and probes as follows [12]:

$$
W_{\mathrm{A}}=2 \sqrt{\gamma_{S}^{\mathrm{D}}} \sqrt{\gamma_{L}^{\mathrm{D}}},
$$

where $\gamma_{S}^{\mathrm{D}}$ is dispersive component of the solid surface energy (i.e. sample whose surface energy is to be determined, stationary phase) and $\gamma_{L}^{\mathrm{D}}$ is dispersive component of the liquid surface energy (in this case, hydrocarbons that are regarded as mobile phase). Combining equations (2), (3) and (4),

$$
\mathrm{RT} \ln V_{\mathrm{N}}=2 N_{\mathrm{A}} \sqrt{\gamma_{S}^{D}} \cdot a \sqrt{\gamma_{L}^{D}}+\mathrm{C} .
$$

Hence, the dispersive surface energy of solid $\left(\gamma_{S}^{\mathrm{D}}\right)$ can be obtained from the slope $\left(2 N_{\mathrm{A}} \sqrt{\gamma_{s}^{\mathrm{D}}}\right)$ of a plot of RT $\ln V_{\mathrm{N}}$ against $a \sqrt{\gamma_{L}^{\mathrm{D}}}$.

The specific free energy $\left(\Delta G^{\mathrm{P}}\right)$ can be determined directly using different polar probes [22, 23]. Each probe interacts with complementary polar sites of the material. For example, an acidic probe such as dichloromethane interacts with basic sites of the material, and therefore, determines the basic character of the material surface. On the other hand, a basic probe such as ethyl acetate interacts with acidic sites of the material and, therefore, determines the acidic component or acidic character of the material. All these polar probes interact due to polar as well as dispersive forces. Therefore, when their behaviour is plotted on the same set of axes used for dispersive surface energy calculation, their data lie above the alkane line, and the magnitude of this deviation is equal to the specific or polar component of the free energy of adsorption or desorption $\left(\Delta G^{\mathrm{P}}\right)$ :

$$
\Delta G=\Delta G^{\mathrm{D}}+\Delta G^{\mathrm{P}} .
$$

The polar surface energies $\left(\gamma^{\mathrm{P}}\right)$ of dichloromethane and ethyl acetate can be calculated 
from specific free energy values $\left(\Delta G^{\mathrm{P}}\right)$ using the Good-van Oss concept [28].

The dispersive surface energy measured by IGC at infinite dilution technique is an indication of the highest energy sites, not of total energy sites. It is important to know the distribution of energy sites on the surface for better prediction of the material behaviour. Surface energy heterogeneity profiles can map surface sites of different energy levels. Thus, they can help predict product characteristics and performance. One of the ways to describe surface energetic heterogeneity is the adsorption potential distribution, which can be calculated from the sorption isotherm [25].

The purpose of this research was to explore the use of IGC to examine potential differential surface energy changes to coarse and ML during storage at $75 \% \mathrm{RH}$ (This RH was chosen as this was consistent with the recommendation of high $\mathrm{RH}$ by International Conference of Harmonization in their guidelines for stability testing of pharmaceuticals.) and to relate these changes to changes in powder properties. IGC was used to determine dispersive, polar and total surface energy, work of cohesion and surface energy heterogeneity using adsorption potential distributions. Physical changes in the lactoses were determined by particle size analyses to indicate particle agglomeration and ability to disperse under shear pressure conditions, and dynamic vapour sorption (DVS) will be used to distinguish between moisture adsorption characteristics and to detect amorphous domains in the lactose powders.

\section{MATERIALS AND METHODS}

\subsection{Materials}

Coarse $\alpha$-lactose monohydrate (Inhalac $120^{\circledR}$, Meggle AG, Wasserburg, Germany) and micronized $\alpha$-lactose monohydrate (produced by micronization and then stored on laboratory shelf at $15-20{ }^{\circ} \mathrm{C}$ at $45-50 \% \mathrm{RH}$ for several months) were used as coarse lactose and ML. High-performance liquid chromatography (HPLC) grade methanol (Merck KGaA, Darmstadt, Germany), Milli-Q grade water (Millipore Corporation, Melsheim, France) and ammonium acetate (BDH Laboratories, Victoria, Australia) were used for HPLC analysis.

\subsection{Methods}

\subsubsection{Surface morphology by Scanning Electron Microscopy}

Approximately $2 \mathrm{mg}$ of powder were sprinkled and glued on metal sample plates and then gold plated with a sputter coater (BAL-TEC SCD 005, Tokyo, Japan) using an electrical potential of $2.0 \mathrm{kV}$ at $25 \mathrm{~mA}$ for $10 \mathrm{~min}$. The surface morphology of powder particles was examined at several magnifications under JEOL JSM 6000F scanning electron microscope at $15 \mathrm{kV}$ (JEOL, Tokyo, Japan).

\subsubsection{Particle size analysis by a Mastersizer 2000}

The particle size of the powders was determined by laser diffraction using a Scirocco cell and Scirocco 2000 dry powder feeder at 1.0 bar pressure in a Malvern Mastersizer 2000 (Malvern Instruments Ltd., Worcestershire, UK). Particle size was analysed with the refractive index of lactose (1.533) and with an estimated imaginary refractive index of lactose (0.1). The average particle size distribution was measured from three replicates of each sample using Malvern Mastersizer software (version 5.22).

\subsubsection{Presence of amorphous content by a DVS}

Lactose samples (ca. $100 \mathrm{mg}$ ) in glass sample pans were placed in the sample 
chamber of a commercial DVS-1 (Surface Measurement Systems Ltd. (SMS), London, UK). Prior to $10 \% \mathrm{RH}$ increments from 0 to $90 \% \mathrm{RH}$ at $25{ }^{\circ} \mathrm{C}$, each sample was dried over nitrogen at $0 \% \mathrm{RH}$. Two cycles (each cycle comprised of one sorption from 0 to $90 \% \mathrm{RH}$ and one desorption from 90 to $0 \% \mathrm{RH}$ ) were completed. Equilibrium moisture content at each increment was determined by a dm/dt of $0.0002 \% \mathrm{~min}^{-1}$.

\subsubsection{Surface energy determination by $I G C$}

The surface energy of both coarse and MLs immediately before and after storage at $75 \% \mathrm{RH}$ for three months was determined by a fully automated IGC system (SMS, London, UK). Prior to each measurement, the system was conditioned for $2 \mathrm{~h}$ at $0 \%$ $\mathrm{RH}$ for samples before storage and at $75 \%$ $\mathrm{RH}$ for samples after storage. GC grade undecane, decane, nonane, octane and heptane were used as probes to measure dispersive surface energy, while dichloromethane and ethyl acetate were used to measure polar energy. All the probes were bought from Fluka, and the concentrations kept at $0.03 \mathrm{p} / \mathrm{p}^{0}$ at $30{ }^{\circ} \mathrm{C}$ for infinite dilution. Methane (Linde) was used to measure dead volume and the flow rate of the carrier gas, helium, was $10 \mathrm{~mL} \cdot \mathrm{min}^{-1}$. The surface energies were calculated by IGC standard analysis software version 1.3 (SMS, London, UK). For each measurement, two separate columns were filled with each lactose sample, and the experiment was replicated three times per filled column. No significant difference between repeats in the same column as well as between different columns filled with powders from the same batch was observed $(P>0.05)$. For surface heterogeneity measurements of both fresh and stored samples, each of heptane, dichloromethane and ethyl acetate was run at concentrations $0.03,0.1$, $0.2,0.3,0.4,0.5,0.6,0.8$ and $0.94 \mathrm{p} / \mathrm{p}^{0}$ at conditioning $\mathrm{RH}$ of $0 \%$, and the analyses were carried out using IGC standard analysis software version 1.21 (SMS, London, UK).

\subsubsection{Storage conditions}

Coarse lactose and ML in open pans were stored for three months in a desiccator having an $\mathrm{RH}$ of $75 \%$ produced by a saturated solution of sodium chloride $(\mathrm{NaCl})$ (BDH laboratories, Melbourne, Victoria, Australia) [6]. Over the study period, the $\mathrm{RH}$ and temperature, monitored by a thermohygrometer (Shinyei TRH-CZ, Osaka, Japan), were observed to be $75 \pm 2 \%$ and $25 \pm 2{ }^{\circ} \mathrm{C}$, respectively.

\subsubsection{Agglomerate strength determination by an Aerosizer}

The aerodynamic particle size of the powders was measured by the time-of-flight method using an Aerosizer (Amherst Process Instruments Inc., USA) in a dry powder dispersion system (aerodisperser). Approximately $5 \mathrm{mg}$ of powder were taken in the sample cup of the aerodisperser. Particle size measurement was conducted at a medium feed rate and a sample run time of $300 \mathrm{~s}$. Different shear pressures $(3.4,10.3,20.7$ and $27.6 \mathrm{kPa}$ ) were used to understand the effect of shear pressure on the agglomerate strength of the powders. The particle size of the mixture was analysed using API Aerosizer software (LD version 7.04). The average particle size distribution was determined from five replicates of each sample.

\subsubsection{Statistical analysis}

All data were subjected to one-way analysis of variance (ANOVA) (SPSS, version 15.0, Chicago, IL, USA). Probability $(P)$ values of $\leq 0.05$ when analysed by post hoc multiple comparisons were considered as statistically significant. 

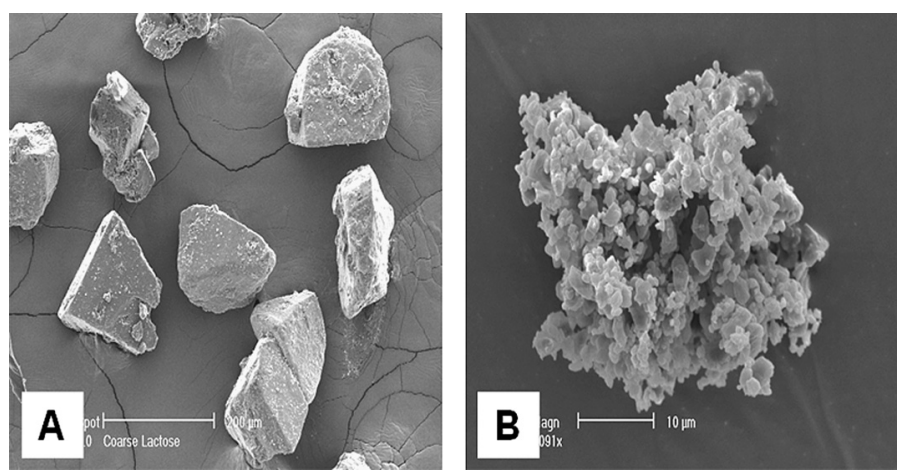

Figure 1. Scanning electron micrograph (SEM) of (A) coarse lactose (magnification $600 \times$ ) and (B) micronized lactose (magnification 5091×).

Table I. Particle size distribution parameters of coarse lactose and micronized lactose before and after storage at $75 \% \mathrm{RH}\left(n=3\right.$, data are shown as mean \pm standard deviation) $\left(d_{10}, d_{50}\right.$ and $d_{90}$ indicate $10 \%, 50 \%$ and $90 \%$ of the volume of particles are less than these particle sizes, respectively).

\begin{tabular}{lcrccc}
\hline Particle size parameter & \multicolumn{2}{c}{ Coarse lactose } & & \multicolumn{2}{c}{ Micronized lactose } \\
\cline { 2 - 3 } \cline { 6 - 6 } & Before storage & After storage & & Before storage & After storage \\
\hline$d_{10}(\mu \mathrm{m})$ & $84.8 \pm 2.3$ & $81.0 \pm 4.2$ & & $0.8 \pm 0.1$ & $1.3 \pm 0.1$ \\
$d_{50}(\mu \mathrm{m})$ & $127.5 \pm 3.8$ & $125.0 \pm 5.2$ & & $2.4 \pm 0.2$ & $3.1 \pm 0.2$ \\
$d_{90}(\mu \mathrm{m})$ & $192.0 \pm 5.5$ & $191.0 \pm 6.1$ & & $5.0 \pm 0.1$ & $5.6 \pm 0.3$ \\
Span & $0.8 \pm 0.1$ & $0.9 \pm 0.1$ & & $1.8 \pm 0.1$ & $1.4 \pm 0.1$ \\
\hline
\end{tabular}

\section{RESULTS AND DISCUSSION}

\subsection{Surface morphology of lactose powders}

The scanning electron microscopy (SEM) of coarse and ML were obtained (Fig. 1). The coarse lactose particles were 'tomahawk' shaped discrete crystals, whereas the ML formed agglomerates because of their relatively high adhesion forces [1].

\subsection{Particle size of lactose powders}

The volume mean diameter (VMD) of coarse lactose was $127.5 \pm 3.8 \mu \mathrm{m}$, having only $0.8 \%<5.0 \mu \mathrm{m}$. Coarse lactose had
$10 \%$ and $90 \%$ of particles $<84.8 \pm 2.3 \mu \mathrm{m}$ and $192.0 \pm 5.5 \mu \mathrm{m}$, respectively (Tab. I). On the other hand, the VMD of ML was $2.4 \pm 0.2 \mu \mathrm{m}$, having $10 \%$ and $90 \%$ of particles $<0.8 \pm 0.1 \mu \mathrm{m}$ and $5.0 \pm 0.1 \mu \mathrm{m}$, respectively.

\subsection{Moisure sorption-desorption isotherms determined by DVS}

DVS data, calculated as percentage of dry mass, are shown in Figure 2. The moisture sorption of ML gradually increased to $0.20 \%(\mathrm{w} / \mathrm{w})$ at $80 \% \mathrm{RH}$ and then jumped to $0.37 \%(\mathrm{w} / \mathrm{w})$ at $90 \% \mathrm{RH}$. Coarse lactose followed a similar trend though 

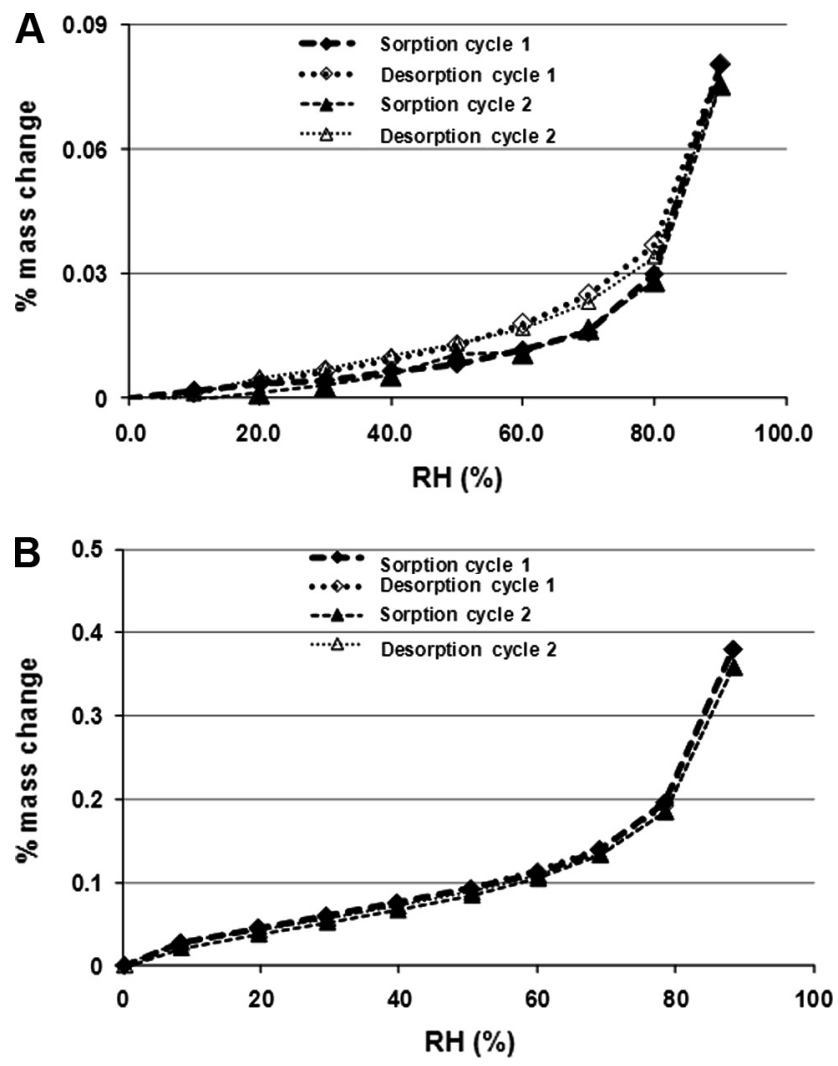

Figure 2. Dynamic vapour sorption isotherms for (A) coarse lactose and (B) micronized lactose.

the extent of moisture sorption was lower. For example, the moisture of coarse lactose was only $0.03 \%(\mathrm{w} / \mathrm{w})$ at $80 \% \mathrm{RH}$ and $0.08 \%(\mathrm{w} / \mathrm{w})$ at $90 \% \mathrm{RH}$. The higher moisture sorption of $\mathrm{ML}$ compared to that of coarse lactose could be attributed to both the surface chemistry and the relative difference in surface area of the lactose powders. The isotherms for coarse lactose showed hysteresis probably due to surface adsorbed water migrating into the bulk during sorption but not during desorption. Comparison of the first and second sorption-desorption isotherm data for both lactose powders showed reversible moisture sorption, suggesting the materials to be crystalline with no detectable amorphous content [29, 30].

\subsection{Surface energy of lactose before storage}

Before storage, the dispersive surface energies $\left(\gamma^{\mathrm{D}}\right)$ of coarse lactose and ML were $39.4 \pm 1.4 \mathrm{~mJ} \cdot \mathrm{m}^{-2}$ and $45.7 \pm 1.3 \mathrm{~mJ} \cdot \mathrm{m}^{-2}$, respectively (Fig. 3). The $\gamma^{\mathrm{D}}$ value for coarse lactose was similar to that reported by Ahfat et al. [2] for $\alpha$-lactose monohydrate $\left(41.4 \mathrm{~mJ} \cdot \mathrm{m}^{-2}\right)$. The polar energy $\left(\gamma^{\mathrm{P}}\right)$ was also significantly $(P<0.05)$ higher for 


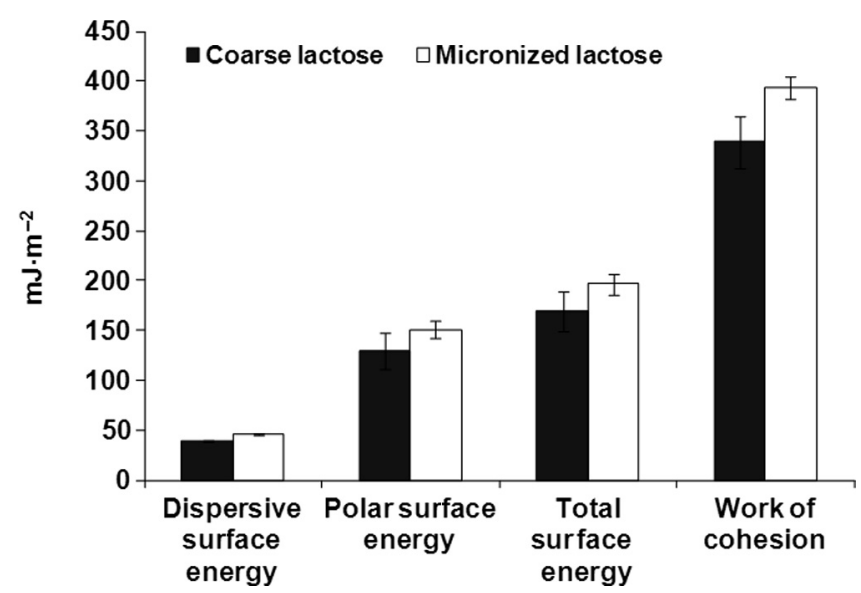

Figure 3. Dispersive, polar and total surface energies and work of cohesion: comparison between coarse lactose and micronized lactose $(n=3$, data are shown as mean with standard deviation by error bar).

ML $\left(150.9 \pm 9.0 \mathrm{~mJ} \cdot \mathrm{m}^{-2}\right)$ than for coarse lactose $\left(129.6 \pm 18.5 \mathrm{~mJ} \cdot \mathrm{m}^{-2}\right)$. Therefore, the total surface energy $(\gamma)$ of $\mathrm{ML}$ $\left(196.6 \pm 9.9 \mathrm{~mJ} \cdot \mathrm{m}^{-2}\right)$ was significantly $(P<0.05)$ higher than that of coarse lactose $\left(169.9 \pm 19.9 \mathrm{~mJ} \cdot \mathrm{m}^{-2}\right)$. The significantly higher surface energy of ML compared to that of coarse lactose could be due to different orientations and spacing between various surface molecules as the surface energy depends on the orientation of molecules on the surface produced during the micronization process $[10,27]$. Micronization of pharmaceutical substances has previously been seen to increase dispersive surface energy $[5,9,11]$.

The work of cohesion for ML was significantly higher $\left(393.5 \pm 12.0 \mathrm{~mJ} \cdot \mathrm{m}^{-2}\right)$ than that for coarse lactose $(339.6 \pm$ $\left.26.0 \mathrm{~mJ} \cdot \mathrm{m}^{-2}\right)(P<0.05)$. The greater work of cohesion of ML was consistent with the stronger particle interactions that were responsible for agglomerate formation as observed by SEM (Fig. 1). In addition, while the increased work of cohesion suggested stronger interactions, the agglomerate formation was also facilitated by a decreased detachment (gravitational) force due to the small particle size and, therefore, mass of the ML particles.

\subsection{Surface energetic heterogeneity determined by IGC}

The surface energy measurements were carried out at infinite dilution. At infinite dilution, probe molecules interact with the highest energy sites that account for $\sim 1-3 \%$ of the surface energy sites [26]. In order to gain knowledge about the less energetic sites on the surface, surface heterogeneity profiles were constructed by gradually increasing probe concentrations. In this study, a non-polar probe, heptane, an acidic probe dichloromethane and a basic probe ethyl acetate were used.

Both lactose powders showed only one peak for interaction with all the probes in the range of adsorption potential (Fig. 4). A monomodal distribution implies only one set of adsorption sites. Examples of heterogeneous surfaces exhibiting more than one peak can be found in the literature [25]. The peak adsorption potential for ML 

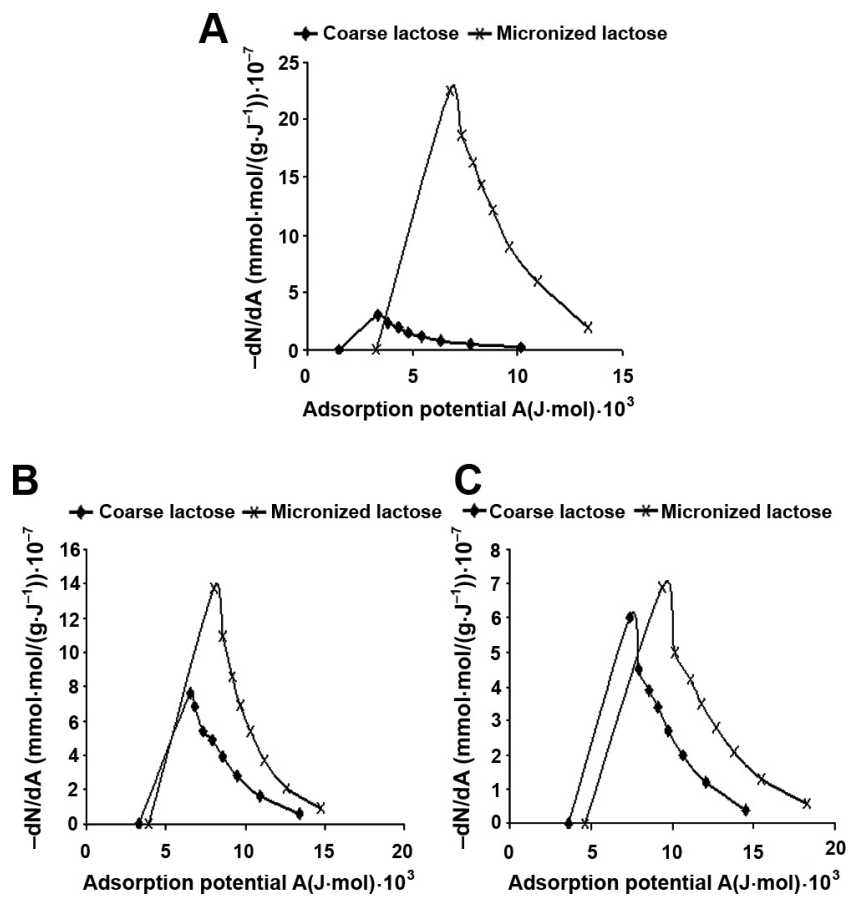

Figure 4. Comparison of surface heterogeneity profiles of coarse lactose and micronized lactose determined using (A) heptane, (B) dichloromethane and (C) ethyl acetate.

was higher than that for coarse lactose for all the probes (Fig. 4). As the peak position is an indication of the energy level of adsorption sites, these results substantiate the presence of higher energy adsorption sites in ML than in coarse lactose. Furthermore, the uptakes of probes, as denoted by the area under the curve (AUC), were lower for coarse lactose than for ML and, therefore, related to fewer interaction sites on the coarse lactose. This may be a consequence of surface area or numbers of inherent sites.

\subsection{Surface energy determined after storage at $75 \% \mathbf{R H}$}

After storage at $75 \% \mathrm{RH}$, the $\gamma^{\mathrm{D}}$ of coarse and micronized lactose significantly decreased to $33.8 \pm 2.3 \mathrm{~mJ} \cdot \mathrm{m}^{-2}(P=0.02)$ and $34.8 \pm 2.3 \mathrm{~mJ} \cdot \mathrm{m}^{-2}(P=0.002)$, respectively (Fig. 5). A decrease in $\gamma^{\mathrm{D}}$ with increasing $\mathrm{RH}$ has been observed previously for stored lactoses [19], cellulose [24] and clays [3]. The total polar energy of both lactose powders significantly increased $(P<0.05)$ after storage. The total polar energy was related to both electron acceptor and donor properties. The total surface energy of micronized lactose significantly increased from $196.6 \pm 9.9 \mathrm{~mJ} \cdot \mathrm{m}^{-2}$ to $247.2 \pm 18.9 \mathrm{~mJ} \cdot \mathrm{m}^{-2}$, whereas that of coarse lactose did not significantly change $(P=0.21)$ (Fig. 5).

The dispersive surface energy was an indication of the interaction of the non-polar probes such as heptane with non-polar surface sites such as hydrophobic rings and long chain hydrocarbons. The polar surface energy involved the interaction of polar 


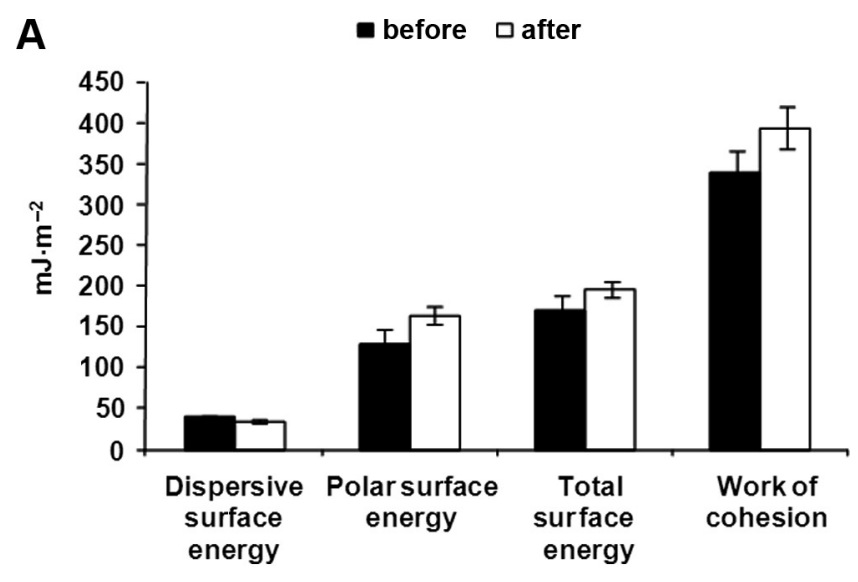

B

- before $\square$ after

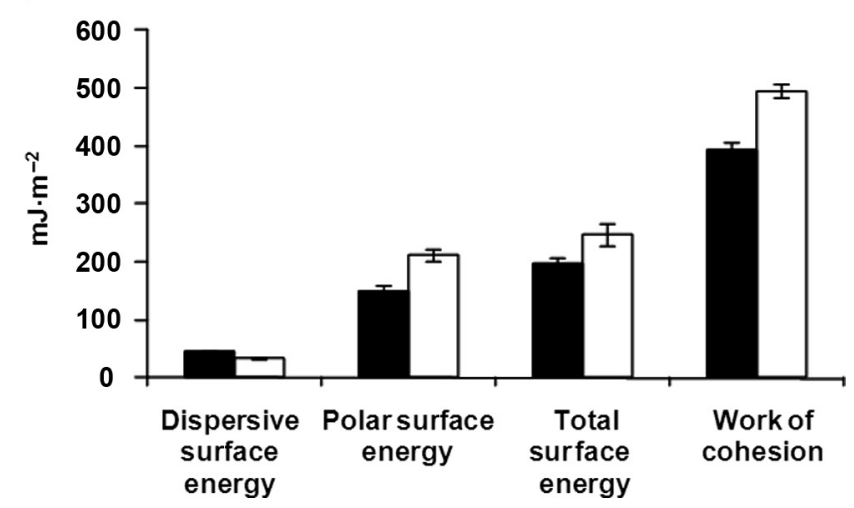

Figure 5. Comparison of dispersive, polar and total surface energies and work of cohesion of (A) coarse lactose and (B) micronized lactose before and after storage at $75 \% \mathrm{RH}$ (before storage sample was conditioned at $0 \% \mathrm{RH}$ for $2 \mathrm{~h}$ while after storage sample was conditioned at $75 \% \mathrm{RH}$ for 2 h) ( $n=3$, data are shown as mean with standard deviation by error bar) (before storage data were shown for comparison).

probes with polar sites. Lactose monohydrate was hydrophilic in nature and was completely wet by water [21]. Lactose has both non-polar (carbon chain and cyclic ring) and polar groups (e.g. - $\mathrm{OH}$ group). During storage at $75 \% \mathrm{RH}$, micronized lactose gained moisture to a greater extent than coarse lactose [8]. Bound surface moisture can provide new polar sites that might interact with the polar probes. As the lactose samples were devoid of any detectable amorphous content, the decrease in the dispersive surface energy of lactoses (both lactose powders) after storage at $75 \% \mathrm{RH}$ (Fig. 5) was likely to result from the shielding of dispersive energy sites, which is consistent with previous reports [7, 19]. The increase in polar surface energy was attributed to the interaction of polar probes with surface moisture of lactose. The total surface energy of micronized lactose increased after storage at $75 \% \mathrm{RH}$ as the increase 
Table II. Comparison of surface heterogeneity profile parameters of coarse lactose and micronized lactose before and after storage at $75 \% \mathrm{RH}$ for three months.

\begin{tabular}{lcccc}
\hline Probes & Lactose samples & \multicolumn{2}{c}{ Surface heterogeneity profile parameters } \\
\cline { 3 - 5 } & & Mode & AUC & Peak adsorption potential \\
\hline Heptane & Coarse lactose & No change & Decreased & Minor right shift \\
& Micronized lactose & No change & Decreased & No shift \\
Dicholoromethane & Coarse lactose & No change & Decreased & No shift \\
& Micronized lactose & No change & No change & Right shift \\
Ethyl acetate & Coarse lactose & No change & No change & No shift \\
& Micronized lactose & No change & No change & Minor left shift \\
\hline
\end{tabular}

in polar surface energy overwhelmed the decrease in dispersive surface energy. The work of cohesion of micronized lactose significantly increased after storage $(P<0.05)$, while that of coarse lactose did not significantly change $(P>0.05)$ (Fig. 5).

\subsection{Surface heterogeneity profiles after storage at $\mathbf{7 5 \%} \mathbf{R H}$}

In general, both coarse lactose and micronized lactoses showed monomodal interaction with all the probes in the adsorption potential range (Tab. II), indicating that surface adsorption sites did not change from a homogeneous to a heterogeneous distribution after storage. For the interaction with heptane, there was no shift in peak adsorption potential for micronized lactose and a very minor shift for coarse lactose after storage. Therefore, these results indicate that there was no major change in the overall energetic status of the powder surfaces after storage. The uptake of heptane, as denoted by the AUC, remarkably decreased for interaction with micronized lactose after storage and could be due to the decreased access of this probe to agglomerated micronized lactose.

The peak for the interaction of dichloromethane with micronized lactose after storage shifted to a higher and more energetic adsorption potential. The peak maximum for interaction with ethyl acetate slightly shifted to a lower adsorption potential for micronized lactose, while that for coarse lactose remained unchanged.

\subsection{Powder properties after storage}

\subsubsection{Particle size}

The VMD of micronized lactose increased from $2.4 \pm 0.2 \mu \mathrm{m}$ to $3.1 \pm 0.2 \mu \mathrm{m}$ after storage, while that of the coarse lactose was unchanged (Tab. I). This increased particle size was an indication of strong agglomerate formation by the micronized lactose particles during storage at the elevated RH. The increased strength of these agglomerates may be due to increased capillary interactions [8]. In order to further understand the changes observed, the span of micronized lactose before and after storage was calculated from PSD and compared (Tab. I). The span was calculated using the following equation:

$$
\operatorname{span}=\{\operatorname{Dv}(90)-\operatorname{Dv}(10)\} / \operatorname{Dv}(50)
$$

where $\operatorname{Dv}(90), \operatorname{Dv}(10)$ and $\operatorname{Dv}(50)$ are the equivalent volume diameters of 90,10 and $50 \%$ cumulative volume undersize, respectively.

The span of the size distribution of ML decreased after storage and the particle size 

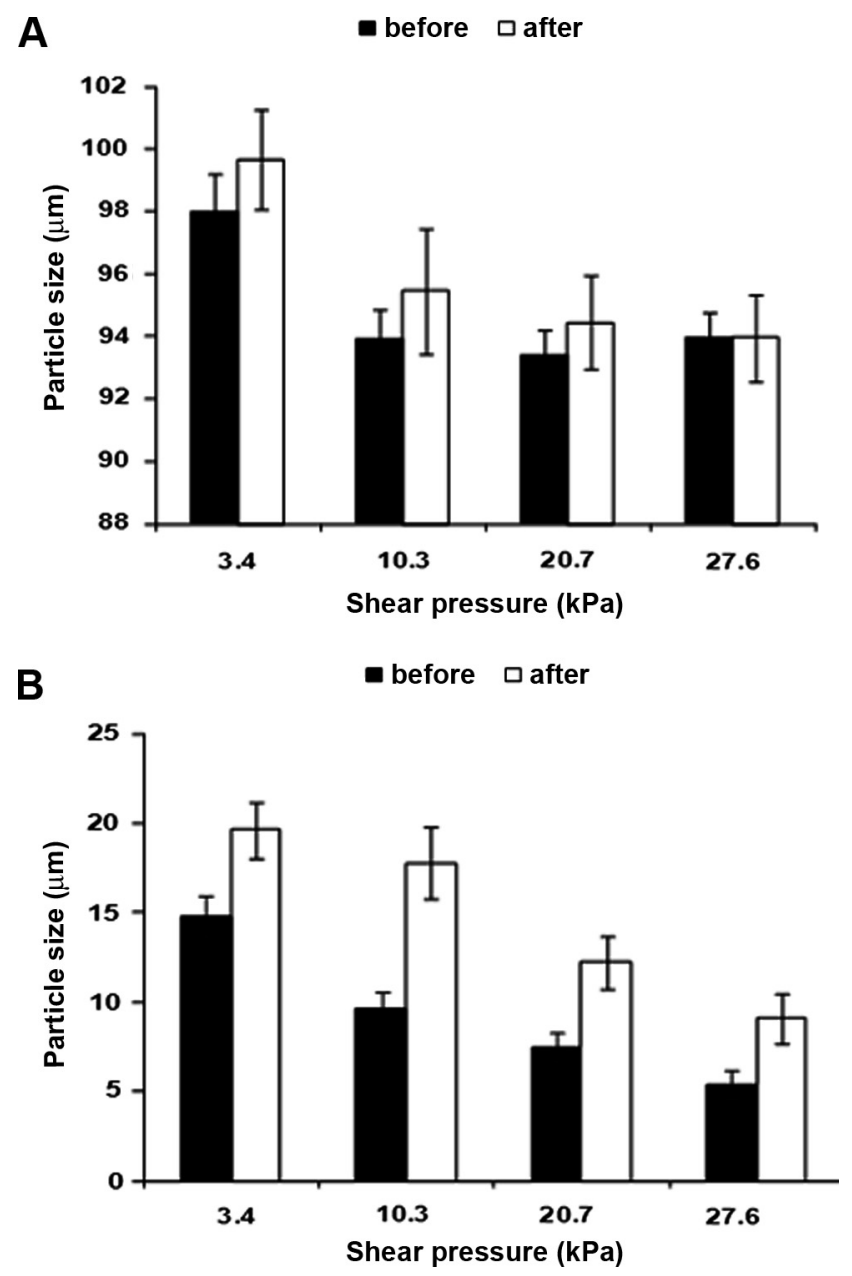

Figure 6. Comparison of particle size-shear pressure of (A) coarse lactose, (B) micronized lactose before and after storage at $75 \% \mathrm{RH}$ for three months and particle size was determined by an Aerosizer at 3.4, 10.3, 20.7 and $27.6 \mathrm{kPa}(n=3$, data are shown as mean with standard deviation by error bar).

distribution indicated a decrease in the number of fine particles. Thus, it is likely that the small particles of the micronized lactose interacted in the high humidity conditions giving larger mean particle sizes resulting in narrower size distributions.

By contrast, the particle size parameters, including the VMD and span, of the coarse lactose were not significantly different after storage $(P>0.05)$.

\subsubsection{Agglomerate properties}

In order to determine a measure of agglomerate strength, the particle sizes of powders were determined when dispersed 
at very low, but increasing shear pressures $(3.4,10.3,20.7$ and $27.6 \mathrm{kPa})$. For the coarse lactose, the particle sizes after storage were not significantly different than before storage $(P>0.05)$ determined at those four different pressures (Fig. 6). In contrast, the particle sizes of micronized lactose $\left(d_{50}\right)$ after storage were significantly higher than before storage. These data indicate that micronized lactose formed strong agglomerates during storage.

\subsection{Relationship between surface energy and physical changes during storage}

The surface energy parameters such as dispersive, polar and total surface energy, the work of cohesion and the surface energy distributions measured by IGC were particularly useful in distinguishing between coarse and micronized lactoses. In these circumstances, the surfaces of micronized and coarse lactose are likely to be very different due to crystal dislocations caused by micronization. While no amorphous domains could be identified by DVS, the surface energies and work of cohesion measured at infinite dilution and the surface heterogeneity profiles allowed the lactose samples to be distinguished.

Although the changes observed in the surface energies measured at infinite dilution and the surface heterogeneity profiles coincided with the changes in physical properties of the lactoses studied, it was difficult to say conclusively that there was a cause and effect relationship. The presence of adsorbed surface moisture shielded dispersive energy sites and acted as polar sites for the probes. Since the inherent moisture adsorption capacity of coarse and micronized lactose was different, the behaviour during storage could be expected to be different, and thus changes observed in the physical properties could not be directly related to inherent surface energy changes in the lactose during storage.
The physical changes observed in the micronized lactose have been shown to be related to increased adhesion caused by increased capillary interactions and perhaps solid bridging [8]. Whether the physical changes also were related to changes in the inherent surface energy and therefore particle interaction due to adsorbed moisture was difficult to say. This was because the effect of adsorbed moisture could not be dissected into its influence in changing polar and dispersive active sites or to its influence in changing inherent surface energy of the micronized lactose surface.

\section{CONCLUSIONS}

The study concluded that IGC was useful to characterize and distinguish between lactoses. Surface energy of micronized lactose was higher than that of coarse lactose, which was probably caused by the surface crystal dislocations due to high energy milling. Amorphous content in micronized lactose was not detected by DVS and did not contribute to the higher surface energy.

The changes in surface energy during storage were attributed to the adsorption of moisture. The dispersive surface energy decreased, while the polar energy increased after storage at high RH. The polar surface energy increases of both coarse and micronized lactoses could be due to the interaction of moisture with polar sites, simultaneously exposing new polar sites for interaction. The decrease in dispersive surface energy of coarse lactose and micronized lactose was probably due to shielding of some non-polar energy sites when moisture interacted with polar energy sites. The increase in total surface energy and work of cohesion of micronized lactose after storage coincided with the formation of larger and stronger agglomerates. While this relationship existed, the increased strength of the agglomerates was probably 
related to capillary interactions between the lactose particles leading to solid bridging.

Acknowledgements: Shyamal Das would like to acknowledge the scholarship support from Monash University through the Faculty of Pharmacy and Pharmaceutical Sciences during his $\mathrm{Ph} . \mathrm{D}$. research. He is also grateful to Dr. Handoko Adi for assistance in DVS and SEM and to Dr. Herbert Chiou of Sydney University for Aerosizer and Mastersizer analyses.

\section{REFERENCES}

[1] Adi H., Larson I., Chiou H., Young P., Traini D., Stewart P., Agglomerate strength and dispersion of salmeterol xinafoate from powder mixtures for inhalation, Pharm. Res. 23 (2006) 2556-2565.

[2] Ahfat N., Buckton G., Burrows R., Ticehurst M., An exploration of inter-relationships between contact angle, inverse phase gas chromatography and triboelectric charging data, Eur. J. Pharm. Sci. 9 (2000) 271-276.

[3] Balard H., Saada A., Siffert B., Papirer E., Influence of water on the retention of organic probes on clays studied by IGC, Clays Clay Miner. 45 (1997) 489-495.

[4] Borgstrom L., Bisgaard H., O'Callaghan C., Pedersen S., Dry powder inhalers, in: Bisgaard H., O'Callaghan C., Smaldone G.C. (Eds.), Drug Delivery to the Lung, Marcel Dekker, New York, USA, 2002, pp. 421-448.

[5] Briggner L., Buckton G., Bystrom K., Darcy P., The use of isothermal microcalorimetry in the study of changes in crystallinity induced during the processing of powders, Int. J. Pharm. 105 (1994) 125-135.

[6] Callahan J., Cleary G., Elefant M., Kaplan G., Kensler T., Nash R., Equilibrium moisture content of pharmaceutical excipients, Drug Dev. Ind. Pharm. 8 (1982) 355-369.

[7] Comte S., Calvet R., Dodds J., Balard H., Surface properties of low specific surface powders using inverse gas chromatography, Powder Technol. 157 (2005) 39-47.

[8] Das S., Larson I., Young P., Stewart P., Influence of storage relative humidity on the dispersion of salmeterol xinafoate powders for inhalation, J. Pharm. Sci. 98 (2008) 1015-1027.
[9] Egawa H., Maeda S., Yonemochi E., Oguchi T., Yamamoto K., Nakai Y., Solubility parameter and dissolution behaviour of cephalexin powders with different crystallinity, Chem. Pharm. Bull. 40 (1992) 819-820.

[10] Feeley J., York P., Sumby B., Dicks H., Determination of surface properties and flow characteristics of salbutamol sulphate before and after micronization, Int. J. Pharm. 172 (1998) 89-96.

[11] Florence A., Salole E., Changes in crystallinity and solubility on comminution of digoxin and observations on spironolactone, J. Pharm. Pharmacol. 28 (1976) 479-480.

[12] Fowkes F., Attractive forces at interfaces, J. Ind. Eng. Chem. 56 (1964) 40-52.

[13] Grimsey I., Feeley J., York P., Analysis of the surface energy of pharmaceutical powders by inverse gas chromatography, J. Pharm. Sci. 91 (2002) 571-583.

[14] Islam N., Stewart P., Larson I., Hartley P., Lactose modification by decantation: are drug-fine lactose ratios the key to better dispersion of salmeterol xinafoate from lactose-interactive mixtures? Pharm. Res. 21 (2004) 492-499.

[15] Louey M., Stewart P., Particle interactions involved in aerosol dispersion of ternary interactive mixtures, Pharm. Res. 19 (2002) 1524-1531.

[16] Lucas P., Anderson K., Staniforth J., Protein deposition from dry powder inhalers: fine particle multiplets as performance modifiers, Pharm. Res. 15 (1998) 562-569.

[17] Matthew J., Price R., The influence of fine excipient particles on the performance of carrier-based dry powder inhalation formulations, Pharm. Res. 23 (2006) 1665-1674.

[18] Newell H., Buckton G., Butler D., Thielmann F., Williams D., The use of inverse gas chromatography to measure the surface energy of crystalline, amorphous and recently milled lactose, Pharm. Res. 18 (2001) 662-666.

[19] Newell H., Buckton G., Butler D., Thielmann F., Williams D., The use of inverse gas chromatography to study the change of surface energy of amorphous lactose as a function of relative humidity and the processes of collapse and crystallisation, Int. J. Pharm. 217 (2001) 45-56.

[20] Ohta M., Buckton G., Determination of the changes in surface energetics of cefditoren pivoxil as a consequence of processing 
induced disorder and equilibration to different relative humidities, Int. J. Pharm. 269 (2004) 81-88.

[21] Podczeck F., Newton J., James M., Influence of relative humidity of storage air on the adhesion and autoadhesion of micronized particles to particulate and compacted powder surfaces, J. Colloid Interface Sci. 187 (1997) 484-491.

[22] Schultz J., Lavielle L., Interfacial properties of carbon fibre-epoxy matrix composites, in: Lloyd D., Ward T., Schreiber H. (Eds.), Inverse Gas Chromatography Characterisation of Polymers and Other Materials, ACS Symposium Ser. 391, American Chemical Society, Washington DC, USA, 1989, pp. 185-202.

[23] Schultz J., Lavielle L., Martin C., The role of interface in carbon fibre-epoxy composites, J. Adh. 23 (1987) 45-60.

[24] Sooben K., Buckton G., Newton J., The measurement of surface energies of materials used in wet granulation under dynamic and moist conditions, Pharm. Sci. Suppl. (2000) 2 .

[25] Thielmann F., Pearse D., Determination of surface heterogeneity profiles on graphite by finite concentration inverse gas chromatography, J. Chromatogr. A 969 (2002) 323-327.

[26] Ticehurst M., York P., Rowe R., Dwivedi S., Characterisation of the surface properties of $\alpha$-lactose monohydrate with inverse gas chromatography used to detect batch variation, Int. J. Pharm. 141 (1996) 93-99.

[27] Trowbridge L., Grimsey I., York P., Influence of milling on the surface properties of acetaminophen, Pharm. Sci. 1 (1998) 310.

[28] Van Oss C., Good R., Chaudhury M., Additive and nonadditive surface tension components and the interpretation of contact angles, Langmuir 4 (1988) 884-891.

[29] Young P.M., Sung A., Traini D., Kwok P., Chiou H., Chan H.K., Influence of humidity on the electrostatic charge and aerosol performance of dry powder inhaler carrier based systems, Pharm. Res. 24 (2007) 963-970.

[30] Zhu K., Tan R.B.H., Ng W.K., Shen S., Zhou Q., Heng P.W.S., Analysis of the influence of relative humidity on the moisture sorption of particles and the aerosolization process in a dry powder inhaler, Aerosol Sci. 39 (2008) 510-524. 